\title{
The antiproliferative effects of somatostatin receptor subtype 2 in breast cancer cells
}

\author{
Yong $\mathrm{HE}^{1, \#}$, Xiao-mei YUAN",\#, Ping LEI ${ }^{2}$, Sha $\mathrm{WU}^{4}$, Wei XING ${ }^{2}$, Xiao-li $\mathrm{LAN}^{1}$, Hui-fen $Z \mathrm{HU}^{2}$, Tao HUANG ${ }^{3}$, Guo-bing WANG ${ }^{3}$, Rui \\ $\mathrm{AN}^{1}$, Yong-xue ZHANG ${ }^{1}$, Guan-xin SHEN ${ }^{2, *}$ \\ ${ }^{1}$ Department of Nuclear Medicine, Hubei Key Laboratory of Molecular Imaging, Union hospital of Tongji Medical College, Huazhong \\ University of Science and Technology, Wuhan 430022, China; ${ }^{2}$ Department of Immunology, Tongji Medical College, Huazhong Univer- \\ sity of Science and Technology, Wuhan 430030, China; ${ }^{3}$ Department of Surgery, Union Hospital of Tongji Medical College, Huazhong \\ University of Science and Technology, Wuhan 430022, China; ${ }^{4}$ Southern Medical University, Guangzhou 510182, China
}

\begin{abstract}
Aim: Somatostatin receptor subtype 2 (SSTR2) is the principal mediator of somatostatin's (SST) antiproliferative effects on normal and cancer cells. Therefore, we investigated whether the enhanced expression of SSTR2 could inhibit the proliferation of tumor cells, and, if so, the mechanisms that might be involved.

Methods: SSTR2 expression levels were determined by qRT-PCR in several tumor cell lines. Then, a plasmid pIRES2-EGFP-SSTR2 (pSIG) was constructed and stably transfected into MCF-7 cells (MCF-7/pSIG). After SSTR2 overexpression was identified by qRT-PCR, immunofluorescence staining and a receptor binding assay, the MCF-7/pSIG cells were analyzed by PI staining for apoptosis and cell cycle arrest was tested by flow cytometry for epidermal growth factor receptor (EGFR) expression. The EGF-stimulated proliferation of MCF-7 cells was assayed by MTT.

Results: The human breast cancer cell line MCF-7 expresses a lower level of SSTR2, thereby partly accounting for the decreased response to SST. The overexpression of SSTR2 in MCF-7 cells resulted in apoptosis, cytostasis and $\mathrm{G}_{1} / \mathrm{S}$ cell cycle arrest. Furthermore, the expression of EGFR, together with EGF-stimulated proliferation, was markedly decreased in the MCF-7/pSIG cells.

Conclusion: Enhanced SSTR2 expression played an antiproliferative role in MCF-7 cells through inducing apoptosis and $\mathrm{G}_{1} / \mathrm{S}$ cell cycle arrest, and also by decreasing EGFR expression, thereby counteracting the growth-stimulating effect of EGF. Our data seem to indicate that developing a new therapeutic agent capable of upregulating SSTR expression could potentially be a way to block tumor progression.
\end{abstract}

Keywords: somatostatin; somatostatin receptor; epidermal growth factor receptor; breast cancer

Acta Pharmacologica Sinica (2009) 30: 1053-1059; doi: 10.1038/aps.2009.59

\section{Introduction}

Somatostatin (SST) is an endogenously produced peptide eliciting both direct and indirect effects on tumor biology ${ }^{[1]}$. The indirect biological effects of SST or its analogs involve the inhibition of hormones and growth factors that promote tumor growth, while the direct effects involve the inhibition of proliferation and/or the induction of apoptosis via interactions with a family of $G$ protein-coupled receptors (GPCRs) with five known subtypes (SSTR1-5) present in tumor cells ${ }^{[1,2]}$. These five distinct SSTRs are distributed in human organs and tumors in a subtype-selective and tissue-specific fashion. Among them, SSTR2 shows the highest affinity for SST

\footnotetext{
* To whom correspondence should be addressed.

"Yong HE and Xiao-mei YUAN contributed equally to this work.

E-mail myjsz@mails.tjmu.edu.cn (Guan-xin SHEN).

Received 2009-01-21 Accepted 2009-04-14
}

analogs and elicits the strongest antiproliferative effect ${ }^{[3]}$. The SSTR2 was also proven to be the subtype mainly responsible for the high ${ }^{111}$ In-DTPA-octreotide uptake in primary breast cancer $^{[4,5]}$.

Several recent reports demonstrated that SSTR expression in breast cancer is down-regulated either in more aggressive, less differentiated tumors ${ }^{[6]}$ or upon antiestrogen treatment $t^{[5,7]}$, which could account for the ineffectiveness of SST treatment of breast tumors in clinical trials. In an attempt to explore whether breast cancer could respond to SSTs after improvement of the SSTRs, plasmid pSIG bearing the SSTR2 gene was constructed to transfect the MCF-7 cell line. Then, the antiproliferative effect of SSTR2 on these cells was investigated.

It is believed that less aggressive and well-differentiated tumors express SSTRs and have better long-term survival rates, whereas many undifferentiated tumors express ErbBs and have poor prognoses ${ }^{[8]}$, indicating an inverse relationship 
between SSTRs and ErbBs. Moreover, SSTRs have been established to be colocalized with ErbBs in MCF-7 and MB-MDA 231 breast cancer cells ${ }^{[9]}$. On the basis of this evidence, we attempt to clarify the interaction between SSTR2 and EGFR, particularly regarding the expression of EGFR and the EGFstimulated proliferation of MCF-7/pSIG cells.

\section{Materials and methods}

\section{Construction of pSIG and stable transfection}

Plasmid pGEM-T-SSTR2 bearing the full sequence of the SSTR2 gene (constructed by our laboratory, data not shown) was used as a template. SSTR2 was amplified using the

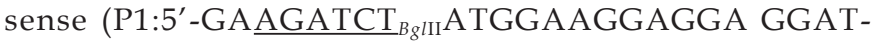
GTGAAGGAGGA 1470 TGGACTGGCGGATGAG-3') and the antisense (P2:5'-AAAA $\underline{\mathrm{CTGCAG}}_{P_{s t \mathrm{I}}} \mathrm{G}_{2634} \mathrm{CCCAT}^{\prime} \mathrm{TGCCA-}$ GTAGACA-3') primers. The PCR products were digested with appropriate restriction enzymes and then subcloned into pIRES2-EGFP (BD Biosciences Clontech, CA, USA) to generate plasmid pSIG. Sequencing was performed using P1 and P2 primers (Invitrogen, Shanghai, China).

Transfection of $0.8 \mu \mathrm{g}$ pSIG into $0.5 \times 10^{5} \mathrm{MCF}-7$ cells was performed using Lipofectamine 2000 (Invitrogen, Carlsbad, CA, USA) according to the manufacturer's recommendations. G418 (Promega, Madison, WI, USA) resistant clones were expanded, harvested and named as MCF-7/pSIG cells. MCF-7 and MCF-7/pIRES2-EGFP cells were treated the same as MCF-7/pSIG cells as mock and vector controls.

SSTR2 mRNA expression assessed by quantitative real-time PCR Total RNA prepared from MCF-7, MDA-MB-231 ${ }^{[10]}$, A549, HepG2 and Hela cells were reverse-transcribed into their respective cDNAs. Equal amounts of cDNA were submitted to PCR, in the presence of SYBR green dye (Qiagen, Hilden, Germany) using the sense (P3:5'-C $\mathrm{C}_{1759}$ TTTCTTGGCTATGCAGGTGG-3') and the antisense (P4:5'-G ${ }_{1862}$ AAGATGCT GGTGAACTGATTG-3') primers. The $\beta$-actin endogenous housekeeping gene was used as an internal control. PCR without template was used as a negative control. Each sample was normalized by using the difference in critical thresholds (CT) between SSTR2 and $\beta$-actin, $\Delta \Delta \mathrm{CT}_{\mathrm{SSTR} 2}=\Delta \mathrm{CT}_{\mathrm{SSTR} 2}-\Delta \mathrm{CT}_{\beta \text {-actin }}$ where $\Delta \mathrm{CT}_{\mathrm{SSTR} 2}$ is the difference in CT between SSTR2 and the negative control, whereas $\Delta \mathrm{CT}_{\beta \text {-actin }}$ is between $\beta$-actin and the negative control. The mRNA levels of each sample were then compared using the expression $2^{-\Delta \Delta C T S S T R 2}$. The expression level for the lowest one was arbitrarily assigned a value of 1 , and the final results were expressed as fold numbers compared to the lowest sample.

The SSTR2 mRNA expression was also compared between various transfected MCF-7 cells by qRT-PCR.

\section{Flow cytometry analysis for SSTR2 expression}

Following incubation with 1:100 dilution of anti-SSTR2 polyclonal antibody (Santa Cruz Biotechnology, Santa Cruz, CA, USA; Catalog \#, sc-11606) for $60 \mathrm{~min}$, cells were cocultured with CY3-conjugated rabbit anti-goat IgG (Sigma, St Louis, MO, USA; Catalog \#, C2821) for $60 \mathrm{~min}$. After being washed and resuspended in PBS, cells were assessed with a flow cytometer (FCM, BD Biosciences, San Jose, CA, USA).

\section{Immunofluorescence assay for SSTR2 expression}

Paraformaldehyde-fixed MCF-7 cells were incubated with anti-SSTR2 polyclonal antibody overnight at $4{ }^{\circ} \mathrm{C}$. Following PBS washing, CY3-conjugated rabbit anti-goat IgG was added. Green and red fluorescence were viewed under a fluorescence microscope (Olympus, Tokyo, Japan). Negative controls were set the same as the FCM analysis.

\section{Internalization studies}

Studies of the internalization of somatostatin receptor-bound ${ }^{125}$ I-labelled ligands (somatostatin analogue [D-Phe1,Tyr3] octreotide (TOC)) were performed. MCF-7 cells were incubated in triplicate with $150000 \mathrm{cpm}{ }^{125} \mathrm{I}$-TOC at $37^{\circ} \mathrm{C}$. After $30,60,90$, and $120 \mathrm{~min}$, cells were rinsed twice. Surface bound radioactivity was removed by incubation with acid buffer (50 $\mathrm{mmol} / \mathrm{L}$ glycine- $\mathrm{HCl} / 100 \mathrm{mmol} / \mathrm{L} \mathrm{NaCl} \mathrm{pH} 2.8$ ) at room temperature for $20 \mathrm{~min}$. After two washing steps, the internalized activity was measured and related to the total activity added.

After 3 washes, trypsin was added and the cells were transferred to scintillation vials for determination of bound radioactivity.

\section{Apoptotic and cell cycle analyses}

MCF-7 cells were cultured with $1 \times 10^{-9} \mathrm{~mol} / \mathrm{L}$ TOC for $72 \mathrm{~h}$. Then cells were fixed with $70 \%$ dehydrated alcohol overnight at $4{ }^{\circ} \mathrm{C}$. Finally, cells were incubated in propidium iodide (PI, Sigma; Catalog \#, 81845) for 20-40 min and assessed with FCM for the cell number in the sub- $G_{0} / G_{1}$ peak (apoptotic peak) and for the DNA content.

\section{Detection for EGFR expression}

TOC treated cells were cocultured with PE-conjugated antiEGFR (1:200 dilution, BD Biosciences; Catalog \#, 555997). After 60 min of incubation, cells were assessed with FCM.

\section{MTT assay for EGF-stimulated proliferation}

2000 TOC treated cells were plated in a 96-well plate. Then cells were treated with epidermal growth factor (EGF, Peprotech EC, London, UK; Catalog \#, AF-100-15) at different concentrations from 0 to $100 \mathrm{ng} / \mathrm{mL}$. After $72 \mathrm{~h}$, the MTT assay (MTT kit, Sigma; Catalog \#, CGD1) was performed according to the protocol. $O D$ values were read at $570 \mathrm{~nm}$. Triplicates were set for each group.

\section{Results}

\section{Expression level of SSTR2 mRNA in different cancer cell lines}

An initial assessment of SSTR2 levels is essential for determining the response to the SST analog. The results of the qRTPCR show that the expression of SSTR2 mRNA in the cancer cell lines varies considerably (Table 1). Among the several cancer cell lines, including the cells originating from neuroendocrine and non-neuroendocrine tumors, the SSTR2 mRNA was least expressed in the human breast adenocarcinoma 
Table 1. mRNA expression of SSTR2 on MCF-7, Hela, HepG2, MDA-MB231, and A549 assessed by qRT-PCR.

\begin{tabular}{lcc}
\hline Cell lines & $\begin{array}{c}\Delta \Delta \text { CT (Avg hSSTR2 } \\
\Delta \text { CT-Avg } \beta \text {-actin } \Delta C T)\end{array}$ & $\begin{array}{c}\text { Normalized hSSTR2 } \\
\text { amount relative to } \\
\text { MCF-7 2 }\end{array}$ \\
\hline MCACT hstR2
\end{tabular}

Cells were plated into 24 -well plates at a density of $0.5 \times 10^{5}$ cells/well and triplicates were set. After total RNA was extracted, $1 \mu \mathrm{g}$ RNA was reversetranscripted. PCR was performed by 40 cycles of $5 \mathrm{~s}$ at $95^{\circ} \mathrm{C}, 10 \mathrm{~s}$ at $60^{\circ} \mathrm{C}$ and $10 \mathrm{~s}$ at $72^{\circ} \mathrm{C}$. Gene expression level was compared to that found in the lowest sample which was arbitrarily assigned the value 1 . $\Delta \Delta \mathrm{CT}$ data are means and standard deviations from three independent experiments.

cell line MCF-7 and to a slightly greater extent in the human MDA-MB-231 breast carcinoma cells; this indirectly reveals the low expression of SSTR2 in breast cancer cells. These results are in accordance with previously published reports ${ }^{[4,9]}$.

\section{The enhanced expression of SSTR2 in MCF-7/pSIG cells}

In order to enhance the expression of SSTR2, MCF-7 cells were transfected with the pSIG plasmid. qRT-PCR revealed that the expression of SSTR2 mRNA in MCF-7/pSIG cells was about 2730-fold greater than that of the control cells (Table 2). FCM analysis (Figure 1A) also confirmed that the red fluorescenceemitting cells rose from $1.63 \% \pm 0.15 \%$ (MCF-7 group) and $2.33 \% \pm 0.75 \%$ (MCF-7/pIRES2-EGFP group) to $49.67 \% \pm 1.35 \%$ (MCF-7/pSIG group). The mean fluorescence intensity of the SSTR2-Cy3-positive populations in the MCF-7/pSIG group also rose, which indicates increased SSTR2 expression in the transfected MCF-7 cells. There were significant differences in the SSTR2 mRNA and protein expression levels between the MCF-7/pSIG group and the negative controls $(P<0.01)$.

Immunofluorescence staining (Figure 1B) shows that MCF-7/pSIG cells could emit both green and red fluores-

Table 2. Comparison of SSTR2 mRNA levels on MCF-7 cells by qRT-PCR.

\begin{tabular}{lcc}
\hline Cell group & $\begin{array}{c}\Delta \Delta \mathrm{CT} \text { (Avg hSSTR2 } \\
\Delta \mathrm{CT} \text {-Avg } \beta \text {-actin } \Delta \mathrm{CT})\end{array}$ & $\begin{array}{c}\text { Normalized hSSTR2 } \\
\text { amount relative to } \\
\text { MCF-7 2 }\end{array}$ \\
\hline MCFCT hSTR2 \\
MCF-7/ pIRES2-EGFP & $13.139 \pm 0.444$ & 1 \\
MCF-7/pSIG & $12.980 \pm 0.563$ & 1.117 \\
\hline
\end{tabular}

Cells were plated into 24 -well plates at a density of $0.5 \times 10^{5}$ cells per well and three duplicates per treatment. Total RNA was extracted with a QIAamp RNA kit. Gene expression level was compared to that found in untransfected sample, arbitrarily assigned the value 1. $\Delta \Delta \mathrm{CT}$ data are means and standard deviations from three independent experiments. cence. Most of the red fluorescence was found at the plasma membrane, whereas the green fluorescence was mainly in the cytoplasm. However, the vector control cells could emit only green fluorescence, and no fluorescence could be detected in the mock control cells. The CY3 red fluorescence indicated not only the expression of SSTR2 but also the location of the SSTR2 protein in the MCF-7/pSIG cells. These results demonstrate the effectiveness with which the pSIG acted.

\section{Receptor binding properties}

The presence of a particular receptor subtype in a tumor cell does not always guarantee that the binding by a ligand will result in activation. Thus, a receptor binding assay was performed. A specific internalization was observed since the internalized activity in control cells was always lower than that in transfected cells. Internalization versus time of ${ }^{125} \mathrm{I}-$ TOC is shown in Figure 2A. A faster internalization was observed, with about $6 \%$ internalized activity after $30 \mathrm{~min}$. The internalized activity increased as the time went by, and reached a value greater than $15 \%$ after $120 \mathrm{~min}$.

The competitive binding assay confirmed that the addition of unlabeled TOC displaced the radioactive TOC from the MCF-7/pSIG cell surface. The addition of greater amounts of unlabeled TOC yielded lower percentages of total binding. The MCF-7/pSIG cells demonstrated high-affinity specific binding of ${ }^{125} \mathrm{I}-\mathrm{TOC}$ at physiologic concentrations (Figure 2B). This proves that the transfection was successful in causing the MCF-7 cell line to express functional cell surface somatostatin receptor protein.

\section{Apoptosis of MCF-7 cells induced by SSTR2 overexpression}

To determine whether SSTR2 overexpression could enhance apoptosis in MCF-7 breast cancer cells, PI staining was performed. The FCM analysis (Figure 3) shows that after the treatment with TOC, $40.40 \% \pm 14.30 \%$ of cells from the MCF-7/ pSIG group were in the sub- $G_{0} / G_{1}$ peak. Even when TOC was absent in the medium, $19.88 \%$ of cells underwent apoptosis (figure not shown). In contrast, the MCF-7 cells or MCF-7/ pIRES2-EGFP cells underwent little apoptosis $(1.31 \% \pm 0.38 \%$ or $10.09 \% \pm 6.18 \%$, respectively, $P<0.01)$. The results indicate that SSTR2 overexpression may induce apoptosis in the MCF-7 cell line and that the apoptotic effect was more significant when SSTR2 interacted with octreotide.

\section{The expression of EGFR in MCF-7 cells was lowered}

EGFR expression clearly promotes growth and survival of tumor cells. EGFRs are as variably distributed in breast tumors and breast cancer cell lines as SSTRs ${ }^{[1]}$. To explore the relationship between the SSTR2 and EGFR, the EGFR levels of SSTR2-overexpressed MCF-7 cells were assessed. The results (Figure 4A) show that after treatment with TOC, the percent of EGFR-expressing cells in the MCF-7/pSIG group was lowered to $64.53 \% \pm 10.05 \%(P<0.01$ vs control). Additionally, there was also some reduction in the fluorescence intensity of the MCF-7/pSIG group, which suggests that the EGFR expression in MCF-7/pSIG cells was also decreased. However, the 


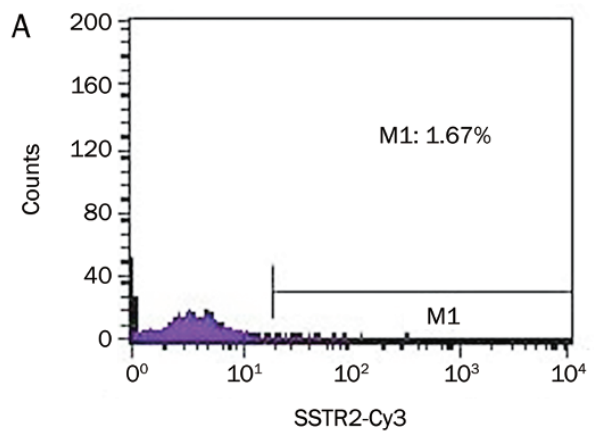

MCF-7

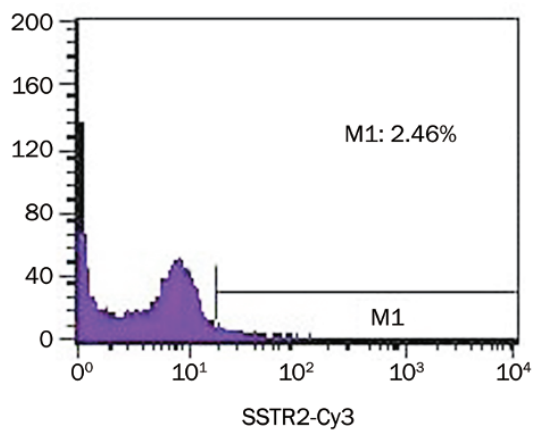

MCF-7/PIRES2-EGFP
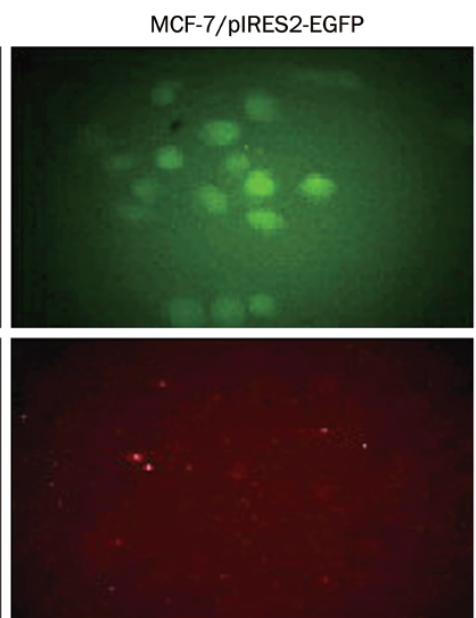
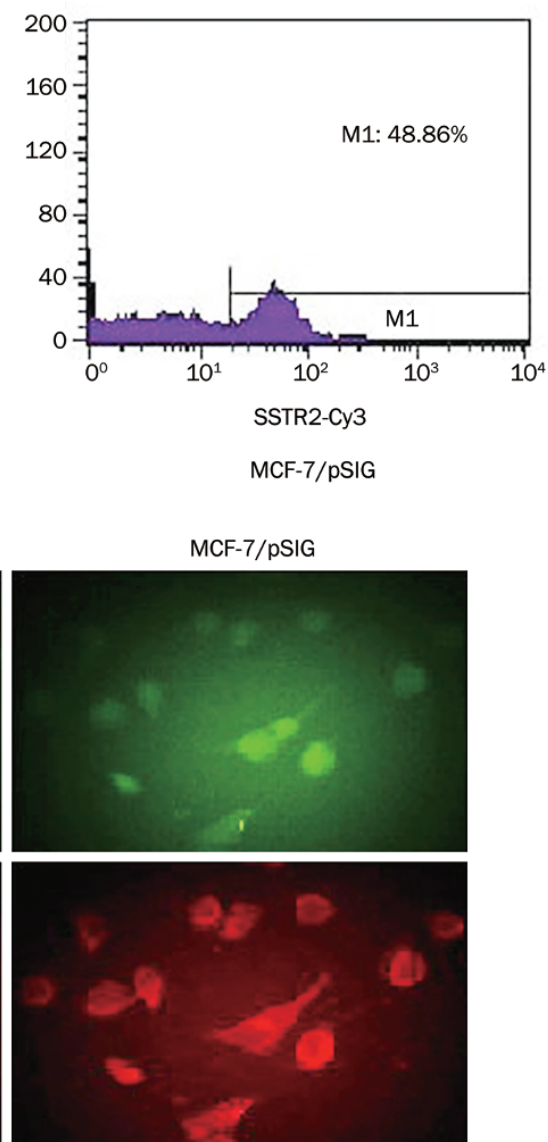

Figure 1. Up-regulation of SSTR2 in MCF-7 cells. (A) Representative FCM photos demonstrating the percentage of SSTR2-expressing cells. After incubation with anti-SSTR2 polyclonal Ab, cells were cocultured with CY3-conjugated rabbit anti-goat IgG and then analyzed by FCM. The M1 gate demarcates the SSTR2-Cy3 positive populations. The percentage of gated cells is indicated. One representative experiment of three is presented. (B) Representative photomicrographs (×400) illustrating MCF-7/pSIG, MCF-7/pIRES2-EGFP, and MCF-7 cells.
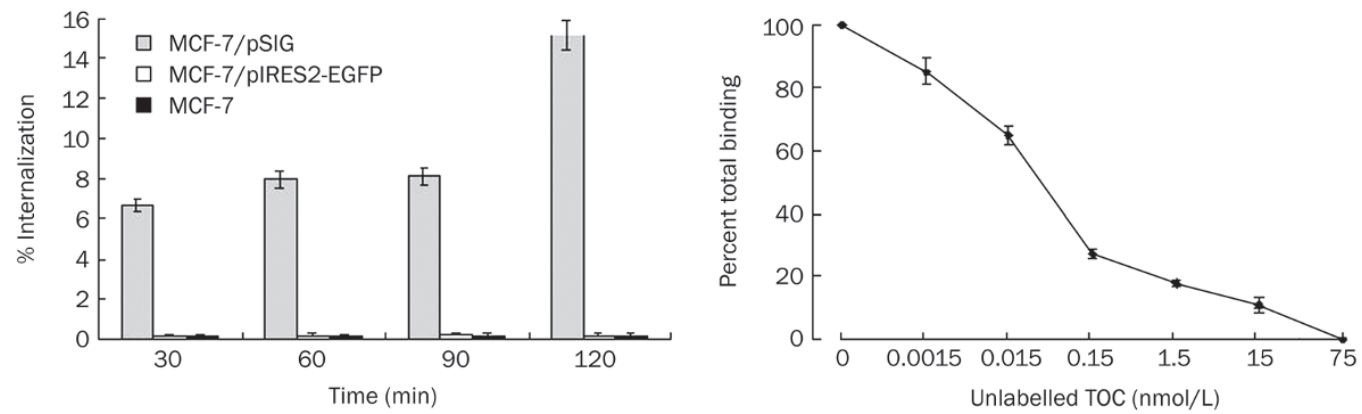

Figure 2. Receptor binding properties. (A) Internalization assay. Cells were incubated with ${ }^{125}$ I-TOC for 30,60 , 90 , and 120 min, respectively. After removal of surface bound radioactivity, the internalized activity was measured and related to the total activity added. (B) Competitive binding assay. Cells were cocultured with $50 \mu \mathrm{L}{ }^{125} \mathrm{I}-\mathrm{TOC}$ and unlabelled TOC in increasing concentrations from 0 to $75 \mathrm{nmol} / \mathrm{L}$ for $1 \mathrm{~h}$ for determination of bound radioactivity. Data are means and standard deviations from three independent experiments.

expression levels of EGFR in both controls remained high, at $93.01 \% \pm 1.92 \%$ (vector control) and $92.14 \% \pm 1.49 \%$ (mock control). Hence, the overexpression of SSTR2 appears to decrease the percentage of EGFR-expressing cells. Furthermore, SSTR2 overexpression was related to a reduction in the EGFR numbers/cell.
In support of biological relevance, the EGF-stimulated proliferation of MCF-7 cells at a physiological concentration was demonstrated by MTT assay. Figure 4B shows that, after treatment with EGF at different concentrations, more MCF-7 control cells exhibited proliferation than MCF-7/pSIG cells. This result indicates that the overexpression of SSTR2 could 

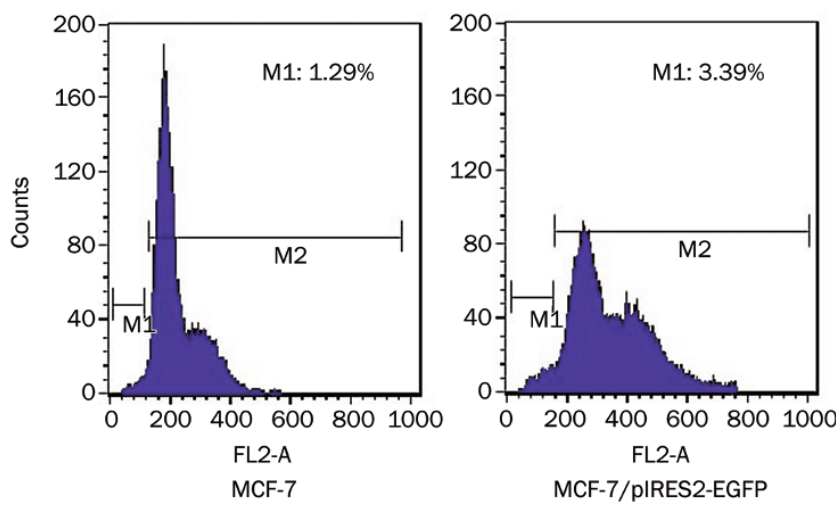

counteract the EGF-stimulated proliferation of MCF-7 cells. Notably, even without EGF stimulation (when the EGF concentration was $0 \mathrm{ng} / \mathrm{mL}$ ), the MCF-7/pSIG cells proliferated less rapidly than the MCF-7 cells. This reconfirmed the antiproliferative effects of SSTR2 in MCF-7 cells.

Cell cycle analysis (Figure 4C) shows that $5.61 \%$ of the MCF-7/pSIG cells were in S phase. That figure rose substantially to $32.52 \%$ and $22.36 \%$ in the untransfected cells and the vector control, respectively. These results show that SSTR2 may mediate the antiproliferative effect in MCF-7 cells.

\section{Discussion}

Many previous studies have indicated that SSTR expression

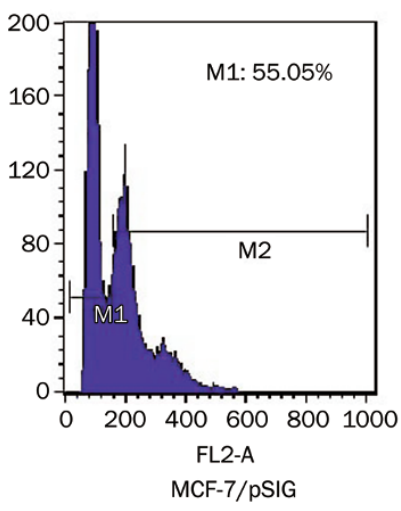

Figure 3. Apoptotic effect of SSTR2 on MCF-7 cells. Representative FCM photos showing the percentage of apoptosic cells. After being fixed with $70 \%$ dehydrated alcohol overnight, TOC-treated cells were stained with $\mathrm{PI}$ and then the cell numbers in the sub- $G_{0} / G_{1}$ peak were analyzed by FCM. The M1 gate demarcates the apoptotic cells. The percentage of gated cells is indicated. One representative experiment of three is presented. may be able to give further insights into conventional prognostic and therapeutic approaches to breast cancer. Published reports have clearly demonstrated the antiproliferative action of SST and its analogs ${ }^{[12,13]}$. Tumor patients with poor prognoses are essentially characterized by a low expression of SSTRs $^{[14,15]}$. In these patients, adjuvant treatment with SST might have little chance of success. Hence, poor expression of SSTR2 in breast cancer may result in the failure of hormonal therapy ${ }^{[16]}$. In the present study, our data showed that at the mRNA level, SSTR2 was lowly expressed in the breast cancer cell lines MCF-7 and MDA-MB-231. Van Den Bossche et al ${ }^{[16]}$ also investigated the pattern of SSTR subtype expression in three other human breast cancer cell lines. They found that
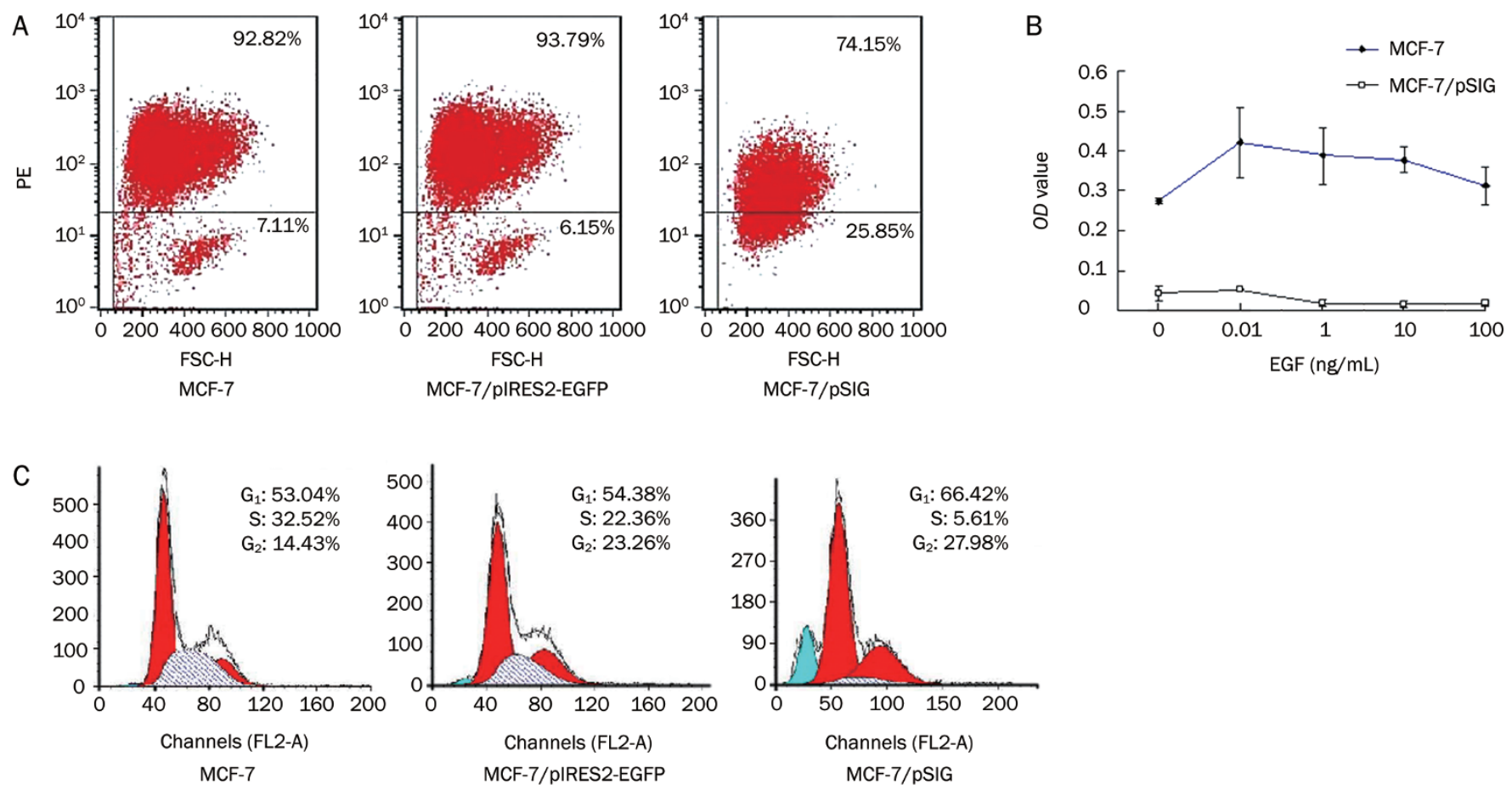

Figure 4. Effect of SSTR2 on EGFR expression and function. (A) Representative FCM photos of the percentage of EGFR-expressing cells. Cells were cocultured with PE-conjugated anti-EGFR and assessed by FCM. One representative experiment of three is presented. (B) EGF-stimulated proliferation. Following treatment with EGF at different concentrations from 0 to $100 \mathrm{ng} / \mathrm{mL}$ for $72 \mathrm{~h}$, cell proliferation was assessed by MTT assay. Data are means and standard deviations from three independent experiments. (C) Representative FCM photos demonstrating the relative percentages of cells in each phase of the cell cycle by PI staining. One representative experiment of three is presented. 
SSTR2 was expressed at comparable levels in T47D, ZR75-1 and MDA-MB-231 cells. Hence, although the SSTR2 mRNA levels in T47D and ZR75-1 were not detected in this paper, given the data obtained from the MDA-MB-231 cells, we could suggest that the expression of SSTR2 appears to be significantly lower in breast cancer cell lines, especially in MCF-7 cells. Although the low expression of SSTR2 in MCF-7 cells was not confirmed by any protein assessment, the results are in accordance with previous reports ${ }^{[4,9]}$.

Since SSTR2 is considered the principal mediator of the antiproliferative effects of SST, an inverse relationship between SSTR2 expression and tumor progression would be expected. In this research, a bicistronic plasmid, pSIG, expressing the human SSTR2 and EGFP genes separately, was constructed with an internal ribosome entry site (IRES) ${ }^{[17]}$. After confirmation of SSTR2 overexpression and SSTR2 binding affinities to the SST analogue TOC, the pSIG was stably transfected into breast adenocarcinoma MCF-7 cells. Our results demonstrated that when the expression was enhanced, SSTR2 exerted obvious antiproliferative effects on the MCF-7 cells, even when no TOC was administrated. A possible explanation could be that the breast cancer cell itself can secrete enough SST. However, whether SST can be synthesized and secreted from these tumor cells remains to be established. According to our study, the SSTR2 subtype may trigger apoptosis as well as cytostasis, although the mechanisms are not clear. To our knowledge, this is the first direct in vitro demonstration of the apoptotic effect of SSTR2 on the MCF-7 breast cancer cell line. Except for where it induces apoptosis, SSTR2 overexpression can also induce cell cycle arrest at the $G_{1} / S$ phase interface.

The growth inhibition elicited by SST and its analogs can occur not only through interaction with the SSTRs present on a tumor cell membrane, but also through the inhibition of hormone and growth factor action ${ }^{[18,19]}$. Increased levels of EGFR gene expression are observed in breast cancers, and they frequently seem to confer a poor prognosis ${ }^{[20]}$. Previous studies revealed the colocalization of SSTR and EGFR ${ }^{[9]}$ and the negative correlation between them ${ }^{[21]}$. Furthermore, the protein-protein interactions or dimerizations between ErbBs and SSTRs are important for signal transduction and are thought to be associated with tumor progression ${ }^{[1]}$. Here we investigated whether enhanced SSTR2 could participate in affecting the expression of EGFR and thereby counteract any deleterious effects of EGF. Although the mechanism remains unknown, our data validated this hypothesis and indirectly verified the crosstalk between the SSTRs and EGFR.

On the basis of the above observation, we concluded that the enhanced SSTR2 expression played an antiproliferative role in the MCF-7 cells through inducing apoptosis and $G_{1} / S$ cell cycle arrest and also by possibly decreasing EGFR expression, thereby reversing the effects of EGF. Altogether, this suggests not only that a mechanism is needed to maintain or upregulate the SSTR2 level on the cell membrane in order to mediate the SST-induced antiproliferative effect, but also that SSTR2 needs to be activated in order to counteract the action of hormones and growth factors. Therefore, developing a new therapeutic agent that could activate SSTRs would potentially be a way to block tumor progression.

\section{Acknowledgements}

The project was supported by grants from the National Natural Science Foundation of China (No 30400112 and № 30270412) and Hubei Key Sci \& Tech. R\&D programme (No 2006AA301A05).

We thank Zhi-hui LIANG for the flow cytometry assays. We thank Jing-fang SHAO, Yue ZHANG, Jing YANG, Wei FENG, Xiao-dan JIANG, Ping XIONG, and Yong XU for expert technical assistance.

\section{Author contribution}

Guan-xin SHEN and Yong HE designed research; Yong HE, Xiao-mei YUAN, Ping LEI, Sha WU, Wei XING and Xiao-li LAN performed research; Tao HUANG, Guo-bing WANG, Rui AN, Yong-xue ZHANG contributed new analytical tools and reagents; Xiao-mei YUAN and Hui-fen ZHU analyzed data; Yong HE, Xiao-mei YUAN and Ping LEI wrote the paper.

\section{References}

1 Watt HL, Kharmate G, Kumar U. Biology of somatostatin in breast cancer. Mol Cell Endocrinol 2008; 286: 251-61.

2 Patel YC, Srikant CB. Somatostatin receptors. Trends Endocrinol Metab 1997; 8: 398-405.

3 Buscail L, Estève JP, Saint-Laurent N, Bertrand V, Reisine T, O'Carroll $\mathrm{AM}$, et al. Inhibition of cell proliferation by the somatostatin analogue RC-160 is mediated by somatostatin receptor subtypes SSTR2 and SSTR5 through different mechanisms. Proc Natl Acad Sci USA 1995; 92: 1580-4.

4 Kumar U, Grigorakis SI, Watt HL, Sasi R, Snell L, Watson P, et al. Somatostatin receptors in primary human breast cancer: quantitative analysis of mRNA for subtypes 1-5 and correlation with receptor protein expression and tumor pathology. Breast Cancer Res Treat 2005; 92: 175-86.

5 Schulz S, Helmholz T, Schmitt J, Franke K, Otto HJ, Weise W. True positive somatostatin receptor scintigraphy in primary breast cancer correlates with expression of sst2A and sst5. Breast Cancer Res Treat 2002; 72: 221-6.

6 Cameron Smith M, Orlando C, Serio M, Maggi M. Somatostatin receptors and breast cancer. J Endocrinol Invest 2003; 26: 125-30

7 Van Den Bossche B, Van Belle S, De Winter F, Signore A, van de Wiele C. Early prediction of endocrine therapy effect in advanced breast cancer patients using ${ }^{99 \mathrm{~m}} \mathrm{Tc}$-depreotide scintigraphy. J Nucl Med 2006; 47: $6-13$

8 Watt and Kumar. Colocalization of somatostatin receptors and epidermal growth factor receptors in breast cancer cells. Cancer Cell Int 2006; 6: 5

9 Reubi JC, Torhorst J. The relationship between somatostatin, epidermal growth factor, and steroid hormone receptors in breast cancer. Cancer 1989; 64: 1254-60.

10 Lacroix M, Leclercq G. Relevance of breast cancer cell lines as models for breast tumours: an update. Breast Cancer Res Treat 2004; 83: 249-89.

11 Wiseman SM, Makretsov N, Nielsen TO, Gilks B, Yorida E, Cheang $\mathrm{M}$, et al. Coexpression of the type 1 growth factor receptor family members HER-1, HER-2, HER-3 has a synergistic negative prognostic effect on breast carcinoma survival. Cancer 2005; 103: 1770-7. 
12 Pawlikowski M, Melen-Mucha G. Somatostatin analogs - from new molecules to new applications, Curr Opin Pharmacol 2004; 4: 60813.

13 Susini C, Buscail L. Rationale for the use of somatostatin analogs as antitumor agents, Ann Oncol 2006; 17; 1733-42.

14 Abel F, Ejeskar K, Kogner P, Martinsson T. Gain of chromosome arm $17 q$ is associated with unfavourable prognosis in neuroblastoma, but does not involve mutations in the somatostatin receptor 2 (SSTR2) gene at 17q24. Br J Cancer 1999; 81: 1402-9.

15 Sestini R, Orlando C, Peri A, Tricarico C, Pazzagli M, Serio M, et al. Quantitation of somatostatin receptor type 2 gene expression in neuroblastoma cell lines and primary tumors using competitive reverse transcription-polymerase chain reaction. Clin Cancer Res 1996; 2: 1757-65.

16 Van Den Bossche B, D'haeninck E, De Vos F, Dierckx RA, Van Belle
$\mathrm{S}$, et al. Oestrogen-mediated regulation of somatostatin receptor expression in human breast cancer cell lines assessed with ${ }^{99 \mathrm{~m}} \mathrm{Tc}$ depreotide. Eur J Nucl Med Mol Imaging 2004; 31: 1022-30.

17 De Felipe P. Polycistronic viral vectors. Curr Gene Ther 2002; 2: 355-78.

18 Ballian N, Brunicardi FC, Wang XP. Somatostatin and its receptors in the development of the endocrine pancreas. Pancreas 2006; 33: $1-12$.

19 YC Patel. Somatostatin and its receptor family. Frontiers Neuroendocrinol 1999; 20: 157-98.

20 Krause DS, van Etten RA. Tyrosine kinases as targets for cancer therapy. N Engl J Med 2005; 353: 172-87.

21 Schally AV, Szepeshazi K, Nagy A, Comaru-Schally AM, Halmos G. New approaches to therapy of cancers of the stomach, colon and pancreas based on peptide analogs. Cell Mol Life Sci 2004; 61: 1042-68. 